\title{
Algerian Registry for Inborn Errors of Immunity in Children: Report of 887 children (1985 - 2021)
}

Abdelghani Yagoubi ( $\sim$ capediatrie@gmail.com )

centre algerois de pediatrie https://orcid.org/0000-0002-5570-8810

Azzeddine Tahiat

Nabila Souad Touri

Mohamed Samir Ladj

Ouardia Drali

Brahim Belaid

Ayda Mohand-Oussaid

Abdelhak Dehimi

Reda Belbouab

Yacine Ferhani

Souhila Melzi

Assia Guedouar

Saliha Hakem

Ouardia Khemici

Yacine Inouri

Yanis Meddour

Saadeddine Dib

Zohra Mansouri

Samir Iddir

Abderrahmane Boufersaoui

Houda Boudiaf

Abderrachid Bouhdjila

Ouardia Ibsaine

Hachemi Maouche

Djazia Dahlouk

Azzedine Mekki

Belkacem Bioud

Zahir Bouzerar

Zoulikha Zeroual

Fadila Benhassine

Dahila Bekkat-Berkani

Soumeya Naamoune

Samir Sofiane Salah

Samia Chaib

Nabila Attal 


\section{Nadia Bensaadi \\ Nadira Bouchair \\ Nacira Cherif \\ Leila Kedji}

Salih Bendeddouche

Mohamed Lamine Atif

Kamel Djenouhat

Nadia Kechout

Reda Djidjik

Keltoum Nafissa Benhalla

Leila Smati

Rachida Boukari

https://orcid.org/0000-0003-1833-8002

\section{Research Article}

Keywords: Inborn Errors of Immunity, Registry, Children, Algeria

Posted Date: March 7th, 2022

DOI: https://doi.org/10.21203/rs.3.rs-1287012/v1

License: (a) (i) This work is licensed under a Creative Commons Attribution 4.0 International License. Read Full License 


\section{Abstract}

Introduction: Inborn errors of immunity (IEI) represent a heterogeneous large group of genetic disorders characterized by susceptibility of affected individuals to recurrent infections, autoimmune/inflammatory diseases, allergies and malignancy. We aim to report for the first time the Algerian registry for IEl in children.

Methods: We describe the characteristics of IEl in Algerian children from the data collected in the Algerian registry for IEl over a long period of 37 years.

Results: Between 1985 and 2021, we included 887 children (530 male, 59.6\%) with a mean age at diagnosis of 3.23y and a mean diagnosis delay of $2 y$. The prevalence rate was estimated at 1.97/100,000 inhabitants or $5.91 / 100,000$ children. The parental consanguinity was found in $52.6 \%$. The most prevalent category was combined immunodeficiencies (CID) (35.5\%) followed by predominantly antibody deficiencies $(24.4 \%)$ and CID with syndromic features (17.9\%). The most predominant diseases were severe CID (120 cases), MHC II deficiency (99 cases), agammaglobulinemia (81 cases), common variable immunodeficiency (74 cases), hyper IgE syndromes (60 patients), ataxia telangiectasia (46 patients), Wiskott Aldrich syndrome (40 patients) and chronic granulomatous disease (39 cases). The clinical presentation was dominated by lower respiratory tract infections (69\%), failure to thrive (38.3\%) and chronic diarrhea (35.2\%). Genetic analysis was performed in 156 patients (17.6\%). The global mortality rate was $28.4 \%$ mainly caused by CID.

Conclusion: This is the first report of the Algerian registry for IEl in children. Data is globally similar to that of Middle East and North African (MENA) registries with high consanguinity, predominance of CID, and significant mortality. This registry highlights the weak points that should be improved in order to provide better patient care.

\section{Introduction}

Inborn errors of immunity (IEI), previously known as "primary immunodeficiencies" (PIDs), are a heterogeneous growing group of more than 450 genetic disorders ${ }^{(1,2)}$ that affect the development and/or the function of the immune system. They are characterized by susceptibility to severe infections, autoimmune/inflammatory disease, allergies and/or malignancy.

Like many rare diseases, IEl suffer from a general lack of awareness, diagnostic challenges and management complexities, leading to high morbidity and mortality ${ }^{(3)}$. Creating a patient registry can be an important tool to define the landscape of these defects, identify regional particularities and prioritize efforts needed to improve diagnosis and treatment of IEI. Moreover, a national registry is very useful to identify all diagnosed patients, to estimate the prevalence of these disorders and to provide data for health-care professionals to improve patient care and to perform scientific research, as well as it is an important tool to convince health authorities to set a national program of awareness and access to adequate management including bone marrow transplantation in children.

Although some specific aspects of IEI have been previously reported in Algerian patients ${ }^{(4-9)}$, a global overview of IEl in Algeria has not been published yet. In this article, we describe epidemiological, clinical, 
etiological, management, and outcome data of IEl diagnosed in Algerian children.

\section{Materials And Methods}

General information about Algeria

Algeria is ranked first country in Africa with more than 2.3 million $\mathrm{km}^{2}$. It includes three main geographical areas: The coastal band in the north; the highlands and steppe areas in the center; the Sahara in the south which covers $87 \%$ of the country's surface. This year 2021 , Algeria has a population of 45 million inhabitants with approximately $33 \%$ of children under 17 years old, and about $90 \%$ of this population lives in the north and the center ${ }^{(10)}$. Due to its history, Algeria is a rich ethnic mix with Berber, Arab, European, Turkish and other origins.

There are currently 17 university hospitals and about 10 public hospitals with academic departments of Pediatrics, most of them located in the north.

The IEl study group

The first Algerian child with IEI was registered in 1985. In 2015, a PID study group as a part of the Algerian Society of Pediatrics performed a retrospective multicenter study on PIDs in Algerian children. Data were collected from 13 pediatric departments and 4 immunology laboratories and results were reported in the 4th congress of the African Society for Immunodeficiency (ASID) ${ }^{(11)}$. This informal registry was updated prospectively with inclusion of newly registered patients from 18 pediatric centers ( 12 centers located in Algiers) and 5 immunology laboratories (all located in Algiers). Since 2020, the members of the abovementioned group (listed authors of this article) met to make this last update reported here and to create a formal registry.

\section{Data collection and content}

In the participating centers, all children aged less than 16 years at time of diagnosis of IEl between 1985 and May 2021 were included. Before 2015, data was obtained retrospectively from patient medical records and entered into a Microsoft Excel database. Since 2015, it has been collected prospectively on a standardized data form and then entered into the computerized database. Recorded information included demographical, clinical, biological (immunological, microbiological and genetic if available), treatment (Antibiotics, immunoglobulin, bone marrow transplantation ...) and outcome data (complications and mortality). All pediatric departments and laboratories of immunology at Algerian University or teaching hospitals were invited to participate in this survey. A steering committee among authors reviewed the database to validate cases and to remove duplicates.

Data was collected and blood samples were analyzed after parent's consent.

Diagnosis and classification 
The diagnosis of IEI was based mainly on clinical and immunological criteria, and on genetic analysis when available. Immunological workup was performed in five experienced laboratories, all of them located in Algiers. Complete blood count and serum immunoglobulin $(\mathrm{lg})$ measurement were performed in all our patients after serological testing for human immunodeficiency virus to rule out a secondary immunodeficiency. Immunophenotyping of lymphocyte subpopulations by flow cytometry was included in the immunological workup since 2003. Other laboratory testing, including IgE level, serum IgG subclasses, antigenic and functional complement measurement, oxidative burst test, post-vaccination antibody response, were performed when needed. Before 2014, genetic analysis was performed only in few patients through a collaborative work with international centers (mainly from United States and France), but currently Algerian laboratories are performing more frequently this analysis in situ or in collaboration with international centers.

As we started registration of our patients in 2015, IEI were classified according to the Primary Immunodeficiency Classification of the International Union of Immunological Societies Expert Committee updated in $2014{ }^{(12)}$. We have continued to use this classification for the following registered patients. IEI were classified in nine categories: (1) Combined immunodeficiencies (CID), (2) CID with syndromic features, (3) Predominantly antibody deficiencies, (4) Diseases of immune dysregulation, (5) Congenital defects of phagocyte number, function or both, (6) Defects in innate immunity, (7) Autoinflammatory disorders, (8) Complement deficiencies, (9) Unclassified PID (instead of phenocopies).

Importantly, we did not include in our registry children with asymptomatic selective IgA deficiency or transient hypogammaglobulinemia of infancy.

\section{Statistical analysis}

Basic descriptive statistical analysis was carried out using Microsoft Excel software.

\section{Results}

In a period of 37 years, we collected 887 children registered from participating clinical pediatric centers (785 patients: $88.5 \%$ ) and from immunology laboratories (102 patients: $11.5 \%$ ). The prevalence rate was $1.97 / 100,000$ inhabitants or $5.91 / 100,000$ children. The number of included patients was steadily increasing, especially after 2017 with about 100 cases per year (Fig. 1). 475 of our patients (66\%) lived in Algiers and neighboring provinces and only 69 patients (7.8\%) lived in the southern regions.

Demographic data

Among the 887 included patients, 530 were male and 357 were female (Sex ratio was 1.48). Parental consanguinity was found in $52.6 \%$ of cases and a history of IEI was noted in 252 families (28.4\%). Mean age at diagnosis was 3.23 years and mean age at onset was 1.22 years. These demographic characteristics are shown by IEl category in (Table 1). 
Table 1

Patient characteristics by IEl category

\begin{tabular}{|c|c|c|c|c|c|c|c|}
\hline Category & $\begin{array}{l}\text { Number } \\
\text { of } \\
\text { patients }\end{array}$ & $\begin{array}{l}\text { Sex- } \\
\text { ratio } \\
(M / F)\end{array}$ & $\begin{array}{l}\text { Consanguinity } \\
\text { (\%) }\end{array}$ & $\begin{array}{l}\text { Family } \\
\text { history } \\
\text { of IEI } \\
(\%)\end{array}$ & $\begin{array}{l}\text { Age } \\
\text { at } \\
\text { onset } \\
\text { (v) }\end{array}$ & $\begin{array}{l}\text { Age at } \\
\text { diagnosis } \\
\text { (v) }\end{array}$ & $\begin{array}{l}\text { Delay of } \\
\text { diagnosis } \\
\text { (y) }\end{array}$ \\
\hline $\begin{array}{l}\text { I. Combined } \\
\text { immunodeficiencies } \\
\text { (CID) }\end{array}$ & 315 & 1.16 & 65.2 & 43.2 & 0.67 & 1.33 & 0.67 \\
\hline $\begin{array}{l}\text { II. CID with } \\
\text { syndromic features }\end{array}$ & 159 & 2.31 & 44.8 & 22.8 & 1.33 & 4.00 & 2.67 \\
\hline $\begin{array}{l}\text { III. Predominantly } \\
\text { antibody } \\
\text { deficiencies }\end{array}$ & 216 & 1.77 & 38.3 & 21.7 & 1.50 & 5.00 & 3.50 \\
\hline $\begin{array}{l}\text { IV. Diseases of } \\
\text { immune } \\
\text { dysregulation }\end{array}$ & 64 & 1.13 & 64.9 & 43.6 & 1.42 & 2.25 & 0.83 \\
\hline $\begin{array}{l}\text { V. Congenital } \\
\text { defects of } \\
\text { phagocyte }\end{array}$ & 69 & 2.28 & 54.0 & 37.7 & 1.17 & 2.92 & 1.75 \\
\hline $\begin{array}{l}\text { VI. Defects in innate } \\
\text { immunity }\end{array}$ & 11 & 0.83 & 20.0 & 27.3 & 0.50 & 0.92 & 0.42 \\
\hline $\begin{array}{l}\text { VII. } \\
\text { Autoinflammatory } \\
\text { disorders }\end{array}$ & 16 & 3.0 & 66.7 & 25.0 & 2.08 & 6.42 & 4.33 \\
\hline $\begin{array}{l}\text { VIII. Complement } \\
\text { deficiencies }\end{array}$ & 5 & 0.66 & 12.5 & 60.0 & 0.83 & 4.58 & 3.75 \\
\hline Unclassified IEI & 32 & 0.56 & 48.3 & 11.4 & 0.58 & 3.42 & 2.83 \\
\hline Global & 887 & 1.48 & 52.6 & 28.4 & 1.22 & 3.23 & 2.0 \\
\hline
\end{tabular}

Distribution of IEI

Patients were distributed into 9 categories as depicted in (Fig. 2). The predominant categories were CID (35.5\%), predominantly antibody deficiencies $(24.4 \%)$ and CID with syndromic features $(17.9 \%)$. The most predominant diseases were Severe CID (120 cases), MHC II deficiency (99 cases), agammaglobulinemia (81 cases), common variable immunodeficiency (74 cases), hyper IgE syndromes (60 cases), ataxia telangiectasia (46 cases), Wiskott Aldrich syndrome (40 cases) and chronic granulomatous disease (39 cases). It should be noted that 139 cases $(15.7 \%)$ had a clinical picture and immunological abnormalities compatible with IEl but could not be classified in a well-defined category. The spectrum of the different IEI diagnosed in our registry is presented in (Table 2). 
Table 2

Different diseases diagnosed in Algerian IEI registry

\begin{tabular}{|c|c|c|c|}
\hline Diseases & $\begin{array}{l}\text { Number of } \\
\text { patients }\end{array}$ & $\begin{array}{l}\% \text { inside the } \\
\text { registry }\end{array}$ & $\begin{array}{l}\% \text { inside the } \\
\text { category }\end{array}$ \\
\hline I. Combined immunodeficiencies (CID) & 315 & 35.5 & 38.1 \\
\hline - SCID & 120 & 13.5 & 4.4 \\
\hline * T-B-NK- & 14 & 1.6 & 20.6 \\
\hline * T-B-NK+ & 65 & 7.3 & 4.1 \\
\hline * T-B+NK- & 13 & 1.5 & 8.9 \\
\hline * T-B+NK+ & 28 & 3.1 & 31.4 \\
\hline - MHC II deficiency & 99 & 11.2 & 5.7 \\
\hline - Omenn syndrome & 18 & 2.0 & 0.9 \\
\hline - CD40 ligand deficiency & 3 & 0.3 & 0.3 \\
\hline - MHC I deficiency & 1 & 0.1 & 0.6 \\
\hline - FCHO 1 deficiency & 2 & 0.2 & 22.9 \\
\hline - Not defined & 72 & 8.1 & \\
\hline II. CID with syndromic features & 159 & 17.9 & 37.7 \\
\hline - Hyper IgE syndrome & 60 & 6.8 & 28.9 \\
\hline - Ataxia Telangiectasia & 46 & 5.2 & 25.2 \\
\hline - Wiskott Aldrich syndrome & 40 & 4.5 & 4.4 \\
\hline - Di George syndrome & 7 & 0.8 & 0.6 \\
\hline - Vici syndrome & 1 & 0.1 & 0.6 \\
\hline - Hereditary folate malabsorption & 1 & 0.1 & 0.6 \\
\hline \multirow{2}{*}{$\begin{array}{l}\text { - Defective Arp2/3 mediated filament } \\
\text { branching }\end{array}$} & 1 & 0.1 & 1.9 \\
\hline & 3 & 0.3 & \\
\hline
\end{tabular}




\begin{tabular}{|c|c|c|c|}
\hline Diseases & $\begin{array}{l}\text { Number of } \\
\text { patients }\end{array}$ & $\begin{array}{l}\text { \% inside the } \\
\text { registry }\end{array}$ & $\begin{array}{l}\% \text { inside the } \\
\text { category }\end{array}$ \\
\hline III. Predominantly antibody deficiencies & 216 & 24.4 & 37.5 \\
\hline - Agammaglobulinemia & 81 & 9.1 & 34.3 \\
\hline - Common variable immunodeficiency & 74 & 8.3 & 7.4 \\
\hline - Hyper IgM & 16 & 1.8 & 6.9 \\
\hline - Selective IgA deficiency & 15 & 1.7 & 1.9 \\
\hline - IgG subclasses deficiency & 4 & 0.5 & 12.0 \\
\hline - Not defined & 26 & 2.9 & \\
\hline IV. Diseases of immune dysregulation & 64 & 7.2 & 32.8 \\
\hline - Familial hemophagocytic & 21 & 2.4 & 23.4 \\
\hline & 15 & 1.7 & 12.5 \\
\hline 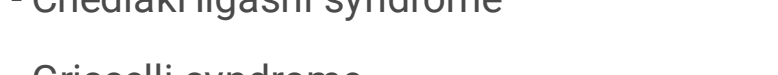 & 8 & 0.9 & 15.6 \\
\hline 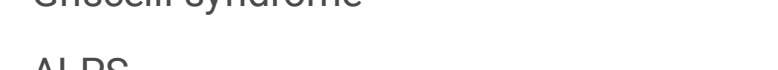 & 10 & 1.1 & 6.2 \\
\hline nLt & 4 & 0.5 & 1.6 \\
\hline -ITEx & 1 & 0.1 & 7.8 \\
\hline - Not defined & 5 & 0.5 & \\
\hline V. Congenital defects of phagocyte & 69 & 7.8 & 56.5 \\
\hline - Chronic granulomatous disease & 39 & 4.4 & 24.6 \\
\hline - Neutropenia & 17 & 1.9 & 14.5 \\
\hline - LAD 1 & 10 & 1.1 & 2.9 \\
\hline - LAD 3 & 2 & 0.2 & 1.4 \\
\hline - Not defined & 1 & 0.1 & \\
\hline VI. Defects in innate immunity & 11 & 1.2 & 54.5 \\
\hline - Chronic mucocutaneous candidiasis & 6 & 0.7 & 45.4 \\
\hline $\begin{array}{l}\text {-Mendelian susceptibility to Mycobacterial } \\
\text { disease }\end{array}$ & 5 & 0.5 & \\
\hline
\end{tabular}




\begin{tabular}{|llll|}
\hline Diseases & $\begin{array}{l}\text { Number of } \\
\text { patients }\end{array}$ & $\begin{array}{l}\text { \% inside the } \\
\text { registry }\end{array}$ & $\begin{array}{l}\text { \% inside the } \\
\text { category }\end{array}$ \\
\hline VII. Autoinflammatory disorders & 16 & 1.8 & 25.0 \\
- Familial Mediterranean fever & 4 & 0.4 & 43.7 \\
- Hyper IgD & 7 & 0.8 & 31.2 \\
- CAPS & 5 & 0.6 & \\
VIII. Complement deficiencies & $\mathbf{5}$ & $\mathbf{0 . 6}$ & \\
\hline Unclassified IEI & 32 & 3.6 & \\
\hline Global & 887 & 100 & \\
\hline
\end{tabular}

Clinical presentation

The clinical presentation observed at diagnosis was dominated by lower respiratory tract infections (69\%), failure to thrive (38.3\%) and chronic diarrhea (35.2\%). Of course, these clinical manifestations depended on the type of IEl. The main clinical signs observed in our registry are presented in (Fig. 3).

Genetic data

Genetic analysis was performed in 156 patients (17.6\%). The most frequently found mutations concerned the MHC II deficiency (59 children), X-linked agammaglobulinemia ( 26 children), severe CID (14 children) and CD18 deficiency (10 children). Some of our patients had mutations with founder effect.

Management

$384(55.6 \%)$ out of the 690 children belonging to the three first categories (CID + CID with syndromic features + predominantly antibody deficiencies) included in our registry were under regular intravenous immunoglobulin replacement therapy. This group included 201 patients with CID (63.8\% of a total of 315 children with CID), 70 had CID with syndromic features (44.0\% of 159 children of this category) and 113 had predominantly antibody deficiencies (52.3\% of 216 children of this category) including 57 (70.4\%) out of 81 agammaglobulinemia and 38 (51.4\%) out of 74 common variable immunodeficiency. Immunoglobulin replacement therapy was well tolerated in almost all patients except for $13(3.1 \%)$ children who had adverse events: rash (10/13), fever (1/13), seizure (1/13) and stroke (1/13).

391 (44\%) children had microbiological data. 557 germs were identified and are detailed in (Table 3). Curative antibiotics, antiviral or antifungal therapies were used mostly on the basis of these microbiological data. Prophylactic antibiotic therapy was prescribed in 497/887 (56\%) patients. It was different depending on the diagnostic category: $60.5 \%$ of patients with congenital defects of phagocyte, $39.8 \%$ of patients with CID, $27.2 \%$ of patients with syndromic CID and $22.3 \%$ of patients with predominantly antibody deficiencies. 
Table 3

Isolated microbes in Algerian IEI registry

\begin{tabular}{|ll|}
\hline Microbes & Number \\
\hline I. Bacteria & 338 \\
- Pseudomonas aeruginosa & 80 \\
- Staphylococcus aureus & 114 \\
- Encapsulated germs & 75 \\
- Mycobacterium tuberculosis & 21 \\
- Others & 48 \\
II. Viruses & 62 \\
- Cytomegalovirus & 28 \\
- Ebstein Barr virus & 14 \\
- Others & 20 \\
\hline III. Fungi & 157 \\
- Aspergillus & 14 \\
- Candida & 109 \\
- Pneumocystisjiroveci & 22 \\
- Cryptosporidium & 12 \\
\hline Global & 557 \\
\hline
\end{tabular}

Hematopoietic stem cell transplantation (HSCT) was performed in 27 patients including 10 children with Wiskott Aldrich syndrome, 3 children with MHC II deficiency, 3 children with chronic granulomatous disease, 3 children with Chediak Higashi syndrome, 3 children with CD40L deficiency, 2 children with SCID, 1 child with hyper IgE syndrome, 1 child with familial hemophagocytic lymphohistiocytosis and 1 child with LAD1. This therapy was performed locally (single center of Pierre et Marie Curie University Hospital) in 9 children. A couple of 4 years old twins with Wiskott Aldrich syndrome underwent gene therapy at 20 months old performed in Italy. They are currently well doing.

Mortality and outcomes

Of the 887 patients, 180 (20.3\%) were lost to follow-up. After exclusion of these patients, the mortality rate was $28.4 \%$ (201/707), but if we consider that these lost patients were deceased the mortality rate increased to $43 \%$ (381/887). Children with CID had the most severe prognosis with $49.2 \%$ of mortality, followed by diseases of immune dysregulation (44.2\%), congenital defects of phagocyte (26.2\%), CID with syndromic features (14.4\%) and predominantly antibody deficiencies (8.2\%). The main cause of death was severe infection in 144 patients (71.6\%). 6 children ( $0.8 \%$ ) had cancers: 5 patients had lymphoma (3 ataxia telangiectasia, 1 SCID, 1 ALPS) and 1 patient (SCID) had sarcoma. 


\section{Discussion}

\section{IEl prevalence}

We present the first report on the distribution of IEI in Algerian children. A total of 887 children were collected in a period of 37 years, thus representing the largest published cohort of IEl patients in Africa and the third largest one in Middle East and North Africa (MENA) $)^{(13,14)}$. Based on a population of 45 million inhabitants in Algeria in 2021, this number of patients represents an estimated prevalence of approximately $2 / 100,000$ inhabitants. But since our registry includes only children, it would be more interesting to estimate the prevalence in this age group of population and as this group represents about $33 \%$ of the general population in Algeria, the adjusted prevalence is approximately $6 / 100,000$ children. This frequency is greater than that found in Morocco $(1.87 / 100,000)$ or Libya $(1.65 / 100,000)$ but remains comparable to that of Tunisia $(6.3 / 100,000)$, even though unlike the current Algerian registry all other Maghreb registries include children and adults $(15,16,17)$.

Although IEI are widely considered rare diseases, they could be more common than generally thought. Following the model proposed by Bousfiha et al. ${ }^{(18)}$ based on an American epidemiological study with a prevalence of $86.3 / 100,000$ inhabitants, the number of IEI patients in Algeria could be estimated at 38835 with approximately 13000 children, without taking into account the high rate of consanguinity in our population. Underestimation of the actual number of patients could be explained by several factors: (1) difficulty in accessing care for many patients due to the distance from diagnostic and treatment centers, mainly concentrated in Algiers, (2) likely existence of many cases died before being diagnosed, (3) existence of cases managed in centers that did not participate in the registry, (4) lack of awareness of IEl by the public and many health professionals leading to under diagnosis of these diseases and finally (5) exclusion of children with asymptomatic selective IgA deficiency or transient hypogammaglobulinemia of infancy.

The incidence of IEI in Algeria is continuously rising. It was less than 6 cases per year before 2003, whereas it reaches 100 cases per year during the last 3 years. Such increase is mainly due to the performance of immunology laboratories which provided since 2003 the basic tests necessary for the diagnosis of the majority of PIDs, and also to the improved awareness of physicians in diagnosing IEI since 2015 when the working group started collecting data to prepare the creation of this registry and reported the preliminary results during the fourth meeting of the African Society for immunodeficiencies that took place in Algiers.

\section{Consanguinity}

A high rate of consanguinity (52.6\%) was found in our registry. Like in all IEl cohorts, this rate is higher than in Algerian general population where consanguinity was estimated at $25 \%{ }^{(19)}$. However, this high consanguinity among IEl patients seems to be a commune feature of MENA region countries $(58.2 \%$ in Tunisia, 43.2\% in Morocco, 54.1\% in Egypt, 78\% in Kuwaitand 75\% in Saudi Arabia) ${ }^{(15,16,20-22)}$. This high rate would explain the high number of autosomal recessive diseases in Algeria and other Arab countries.

\section{IEl distribution}


In our registry, CIDs werethe most common (35.5\%) followed by predominantly antibody deficiencies (24.4\%) and CIDs with syndromic features (17.9\%). This predominance of CID category was also found in other Arab countries such as Tunisia ${ }^{(16)}$, Egypt ${ }^{(20)}$, Kuwait ${ }^{(21)}$ and Saudi Arabia ${ }^{(22)}$ with $28.6 \%, 30 \%, 31.8 \%$ and $59.7 \%$ respectively, whereas predominantly antibody deficiencies were the most common in Iranian (23), European ${ }^{(24)}$, Latin-American ${ }^{(25)}$ and American ${ }^{(26)}$ registries with $30 \%, 50.5 \%, 52 \%$ and $52 \%$ respectively (Fig. 4). Such contrast between Arab and western countries may be related to the consanguinity rate and to a specific genetic background of Arabian MENA countries. Indeed, 99 out of the 315 patients with CID had MHC class II deficiency (31.4\% of CIDs and $11.2 \%$ of total IEl cases in our registry), which is mainly caused by a RFXANK founder mutation (i.e., a 26 bp deletion named I5E6-25_I5E6+1, also known as 752delG26) ${ }^{(5,6 \text {, }}$ 27). MHC class II deficiency is also common in other Arab countries, including Tunisia (7.9\%), Morocco (6.7\%), Kuwait (5.4\%) and Saudi Arabia (12.4\%) while its prevalence is very low in Iran (0.1\%), Latin America $(0.2 \%)$ and USA $(0.04 \%)$. Another possible explanation for CID predominance is the absence of adult patients in our registry, knowing that the most frequent IEl type in adults is CVID.

\section{Genetic diagnosis}

Although many IEls can be characterized from clinical and immunological data, genetic analysis is an important step in classifying the IEI more accurately. Of course, the search for genetic mutations differs from one country to another and depends on the possibilities available to each. Indeed, the percentage of genetic diagnosis varied from $5.1-22.2 \%$ in Africa, from $30.2-69 \%$ in the Middle East, from $3.7-59.4 \%$ in the Far East, from 8.8-57.3\% in Europe, an average of 18\% in Latin America and $45.8 \%$ in the United States (14). In Algeria, the genetic diagnosis has increased from 11 patients $(2.7 \%)$ in 2015 to $156(17.6 \%)$ in this last report. This has been possible thanks to the efforts of local immunologists and to the collaboration with international teams. Further efforts are needed to raise awareness and improve collaboration with Algerian geneticists in the framework of the national registry. This will help to decrease the rate of unclassified IEls.

\section{Mortality}

The overall mortality in our study was at least $28.4 \%$. Similar mortalities were reported in other MENA registries, with $28.8 \%, 34,5 \%, 23,4 \%$, and $26 \%$ in Moroccan, Tunisian, Egyptian and Kuwaiti registries, respectively $(15,16,21,28)$. Mortality was higher in CID patients both in our cohort and other Arab registries; it ranged from $44-56 \%(15,16,21,28)$. In contrast with our finding, the global mortality was low in Saudi Arabia registry $(10.3 \%)$ and the mortality in the CID category was only $11.7 \%{ }^{(22)}$. In Europe, where antibody deficiencies are predominant ( $50.5 \%$ vs. only $10.3 \%$ for CID), the global mortality rate was $9.3 \%{ }^{(24)}$. The high mortality rate in Algeria highlights the importance of an early and efficient management of patients with CID which requires an early diagnosis through neonatal screening. The majority of CID patients require HSCT, this therapy is not yet sufficiently available in Algeria. Indeed, it has been performed locally only in 9 patients. We hope that awareness from the registry data will allow the development of this therapy in our country.

\section{Conclusion}


This registry provided an overview of the IEI situation in Algeria. Several similarities regarding the IEI epidemiology were found with other registries from the MENA region, such as high consanguinity rate, predominance of CIDs and significant mortality. Efforts should be made to strengthen the involvement of all physicians caring for these patients, increase the number of immunology laboratories to allow basic testing in the different regions of the country, improve collaboration with geneticists to better classify our patients, develop neonatal screening for SCID, make HSCT available for children with IEI and develop home-based care. All of this will improve the quality of care, the quality of life for our patients and reduce mortality. The current data is only for children, the involvement of adult physicians is needed to include adult patients and facilitate the child to adult transition.

\section{Declarations}

Acknowledgements: We want to pay tribute to the late Professor Mourad Baghriche, the first Algerian pediatrician who took a close interest in IEI. He was also the first reporter of our study group in international meetings. We would like to thank all the healthcare services involved in this study. We express our gratitude for all the patients and their families.

Funding: No funding to declare.

Conflict of interest: The authors declare no competing interests.

Data availability: The raw data supporting the conclusions of this article will be made available by the authors, without undue reservation.

\section{Author contribution:}

(1) The conception and design of the study.

(2) Acquisition of data

(3) Analysis and interpretation of data

(4) Drafting the article

(5) Revising it critically for important intellectual content

(6) Approval of the final version to be submitted

(7) Agree to be accountable for all aspects of the work in ensuring that questions related to the accuracy or integrity of any part of the work are appropriately investigated and resolved.

AY, LS, RBo (1,2,3,4,5,6,7); AT (2,3,4,5,6,7); NST, MSL, OD, BB, AM, AD, RBe, YF, SM, AG, SH, OK, YI, YM, SN, SD, ZM, SI, ABouf, HB, ABouh, OI, HM, DD, AM, BB, ZB, ZZ, FB, DB, SSS, SC, NA, NBe, NBo, NC, LK, SB, KD, NK, RD $(2,3,5,6,7)$; MLA $(3,5,6,7) ; \operatorname{KNB}(1,2,3,5,6,7)$. 
Ethics statement: This study involving human participants was reviewed and approved by Local Ethics Committee of Mustapha Bacha University Hospital, Algiers, Algeria.

Consent to participate: Informed consent to participate in this study was provided by the participants' parent.

All authors read and approved the final manuscript and consented for publication

\section{References}

1. Tangye SG, Al-Herz W, Bousfiha A, Chatila T, Cunningham-Rundles C, Etzioni A, et al. Human inborn errors of immunity: 2019 update on the classification from the international union of immunological societies expert committee. J Clin Immunol. 2020;40:24-64.

2. Tangye SG, Al-Herz W, Bousfiha A, Cunningham-Rundles C, Franco JL, Holland SM, et al. The everincreasing array of novel inborn errors of immunity: An interim update by the IUIScommittee. J Clin Immunol. 2021;41:666-79.

3. Lopes JP, Cunningham-Rundles $\mathrm{C}$. The importance of primary immunodeficiency registries. The United States immunodeficiency network registry. Immunol Allergy Clin N Am. 2020;40:385-402.

4. Tahiat A, Djidjik R, Boushaki S, Cherguelaine K, Gharnaout M, Boumedine S, et al. Common variable immunodeficiency (CVID): clinical and immunological features of 29 Algerian patients. Pathol Biol. 2014;62:377-81.

5. Djidjik R, Messaoudani N, Tahiat A, Meddour Y, Chaib S, Atek A, et al. Clinical, immunological and genetic features in eleven Algerian patients with major histocompatibility complex class II expression deficiency. Allerg Asthma Clin Immunol. 2012. doi:10.1186/1710-1492-8-14.

6. Kechout N, Attal N, Kaddache C, Touri N, Smati L, Benhalla NK, et al. MHCll deficiency: clinical and molecular findings. Rev Alg Immunol Immunopath. 2015;4(S1):22-6.

7. Boushaki S, Tahiat A, Meddour Y, Chan KW, Chaib S, Benhalla N, et al. Prevalence of BTK mutations in male Algerian patterns with agammaglobulinemia and severe B cell lymphopenia. Clin Immunol. 2015;161:286-90.

8. Kechout N, Touri N, Saidani K, Dehimi A, Ladj S, Ferhani Y, et al. Leukocyte adhesion deficiency type1 in Algeria. Meta gene 2020. doi: 10.1016/j.mgene.2020.100746.

9. Tahiat A, Yagoubi A, Ladj MS, Belbouab R, Aggoune S, Atek L, et al. Diagnostic and predictive contribution of autoantibodies screening in a large series of patients with primary immunodeficiencies. Front Immunol. 2021. doi:10.3389/fimmu.2021.665322.

10. National office of statistics. https://www.ons.dz/.

11. Baghriche M, Smati L, Yagoubi A, Benhalla KN, Kaddache C, Cherif N, et al. Introduction to primary immunodeficiency diseases in Algeria. Rev Alg Immunol Immunopath. 2015;4(S1):9-13.

12. Al-Herz W, Bousfiha A, Casanova JL, Chatila T, Conley ME, Cunningham-Rundles C, et al. Primary immunodeficiency diseases: an update on the classification from the international union of 
immunological societies expert committee for primary immunodeficiency. Front Immunol. 2014. doi:10.3389/fimmu.2014.00162.

13. Aghamohammadi A, Rezaei N, Yazdani R, Delavari S, Kutukculer N, Topyildiz E, et al. Consensus Middle East and North Africa registry on inborn errors of immunity. J Clin Immunol. 2021. doi:10.1007/s10875021-01053-z.

14. Abolhassani H, Azizi G, Sharifi L, Yazdani R, Mohsenzadegan M, Delavari S, et al. Global systematic review of primary immunodeficiency registries. Exp Rev Clin Immunol. 2020;16:717-32.

15. Bousfiha A, Jeddane L, El Hafidi N, Benajiba N, Rada N, El Bakkouri J, et al. First report of the Moroccan registry of primary immunodeficiencies: 15 years of experience (1998-2012). J Clin Immunol. 2014;34:459-68.

16. Mellouli F, Ben Mustapha I, Ben Khaled M, Besbes H, Ouederni M, Mekki N, et al. Report of the Tunisian registry of primary immunodeficiencies: 25 years of experience (1988-2012). J Clin Immunol. 2015;35:745-53.

17. Bousfiha A, Errami A, Jeddane L, Mellouli F, Reda SM, Adeli M, et al. Primary immunodeficiencies: Epidemiology in the Maghreb. Tunis Med. 2018;96:672-7.

18. Bousfiha A, Jeddane L, Ailal F, Benhsaien I, Mahlaoui N, Casanova JL, et al. Primary immunodeficiency diseases worldwide: More common than generally thought. J Clin Immunol. 2013;33:1-7.

19. Benallegue A, Kedji F. Consanguinity and public health. An Algerian study. Arch fr Pédiatr. 1984;41:43540.

20. Galal N, Meshaal S, El-Hawary R, Abdelaziz D, Alkady R, Lotfy S, et al. Patterns of primary immunodeficiency disordersamong a highly consanguineous population: Cairo university pediatric hospital's 5-year experience. J Clin Immunol. 2016;36:649-55.

21. Al-Herz W, Al-Ahmed M, Al-Khabaz A, Husain A, Sadek A, Othman Y. The Kuwait national primary immunodeficiency registry 2004-2018. Front Immunol. 2019. doi:10.3389/fimmu.2019.01754.

22. Al-Saud B, Al-Mousa H, Al-Gazlan S, Al-Ghonaium A, Arnaout R, Al-Seraihy A, et al. Primary immunodeficiency diseases in Saudi Arabia: a tertiary care hospital experience over a period of three years (2010-2013). J Clin Immunol. 2015;35:651-60.

23. Abolhassani H, Kiaee F, Tavakol M, Chavoshzadeh Z, Mahdaviani SA, Moomen T, et al. Fourth update on the Iranian national registry of primaryimmunodeficiencies: Integration of molecular diagnosis. $J$ Clin Immunol. 2018;38:816-32.

24. [Cited. Sept 22 2021]. https://cci-reporting.uniklinik-freiburg.de/\#/.

25. [Cited. Sept 22 2021]. https://lasidregistry.org/view/statistics/general/2021-08.

26. [Cited. Sept 22 2021]. https://usidnet.org/registry-data/stats-registry-enrollment/.

27. Ouederni M, Vincent QB, Frange P, Touzot F, Scerra S, Bejaoui M, et al. Major histocompatibility complex class II expression deficiency caused by a RFXANK founder mutation: a survey of 35 patients. Blood. 2011;118:5108-18.

28. Reda SM, Afifi HM, Amine MM. Primary immunodeficiency diseases in Egyptian children: A singlecenterstudy. J Clin Immunol. 2009;29:343-51. 
Figures

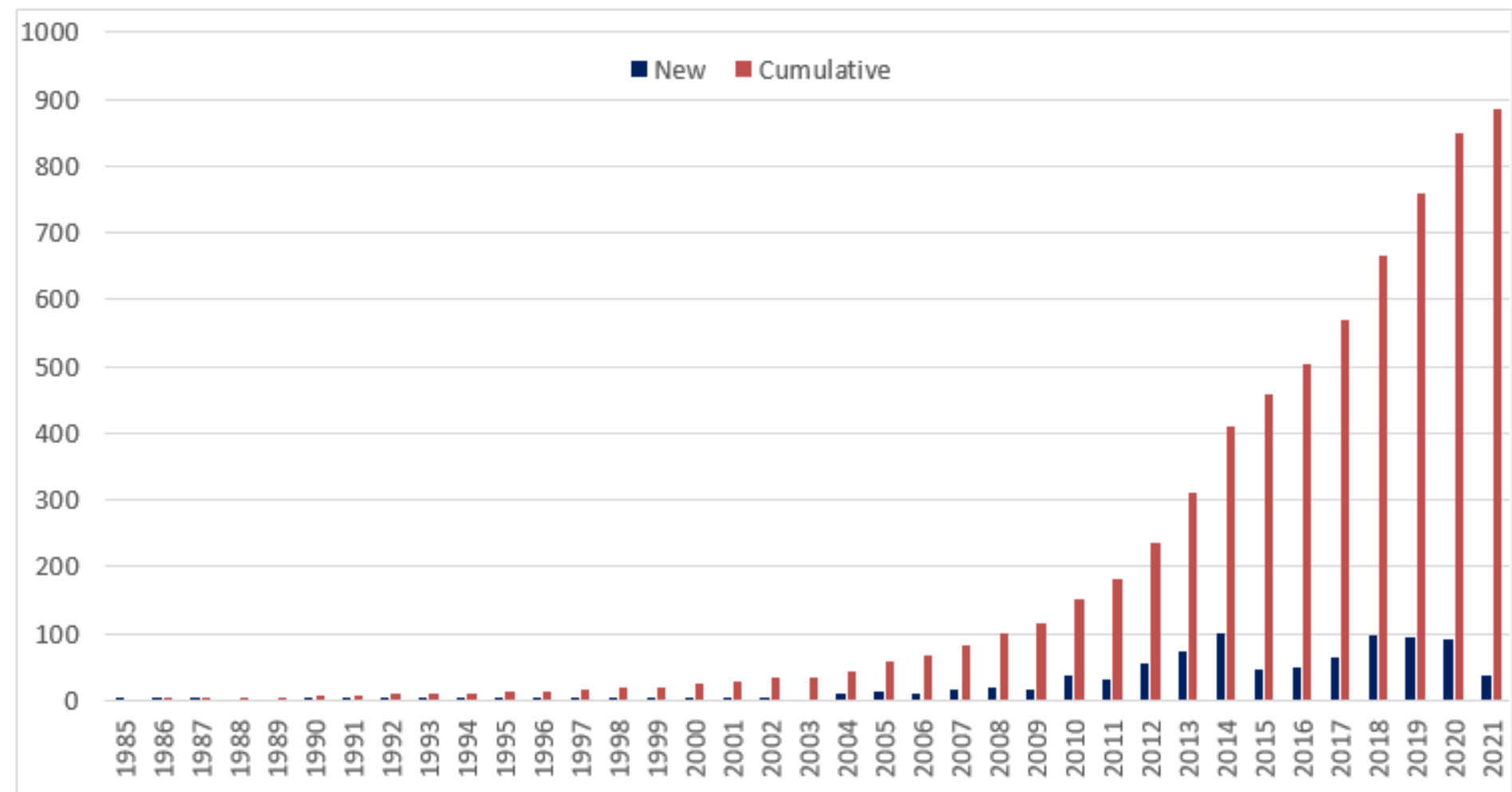

Figure 1

Evolution of IEl incidence in Algeria 


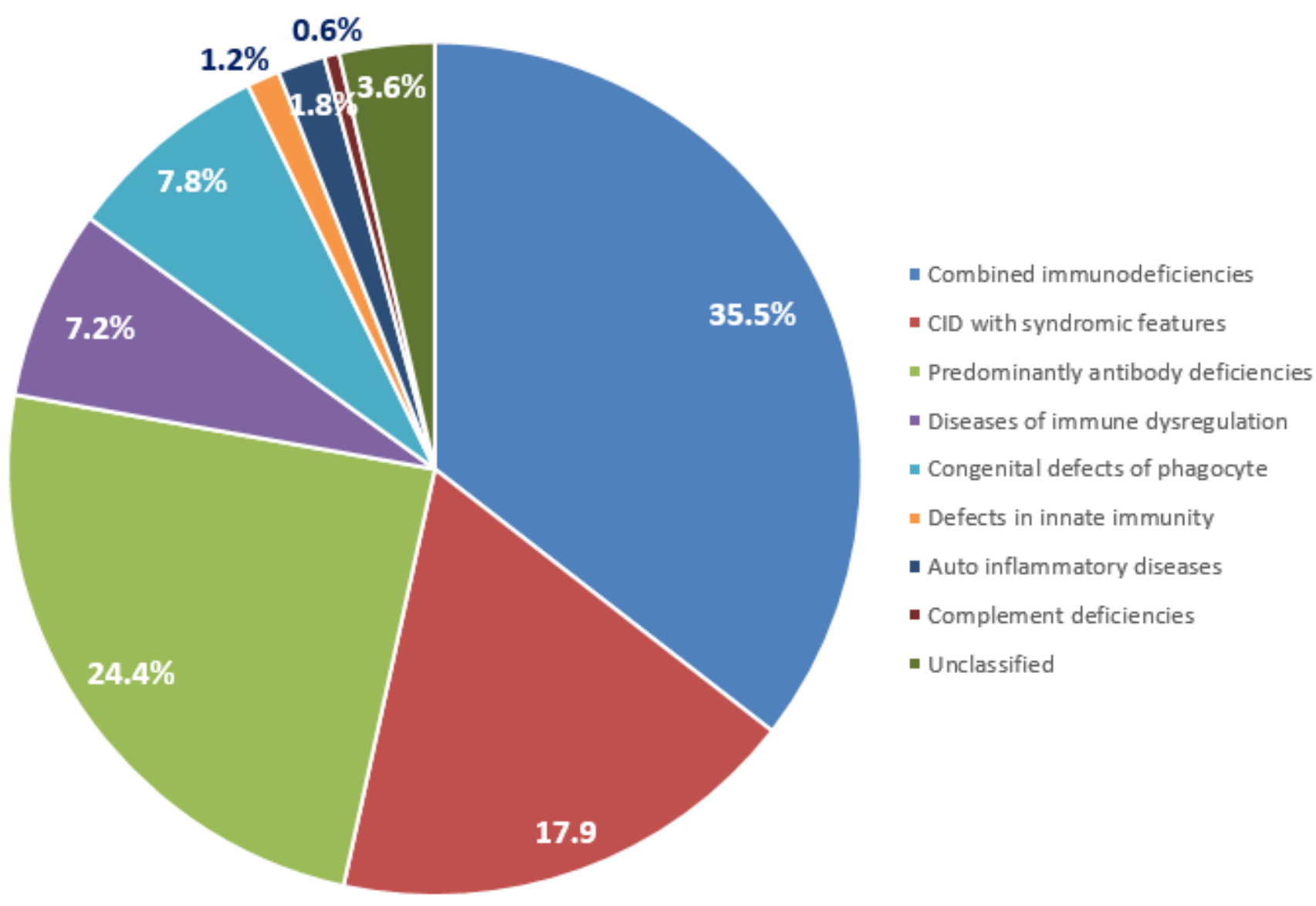

Figure 2

Distribution of patients by IEI category

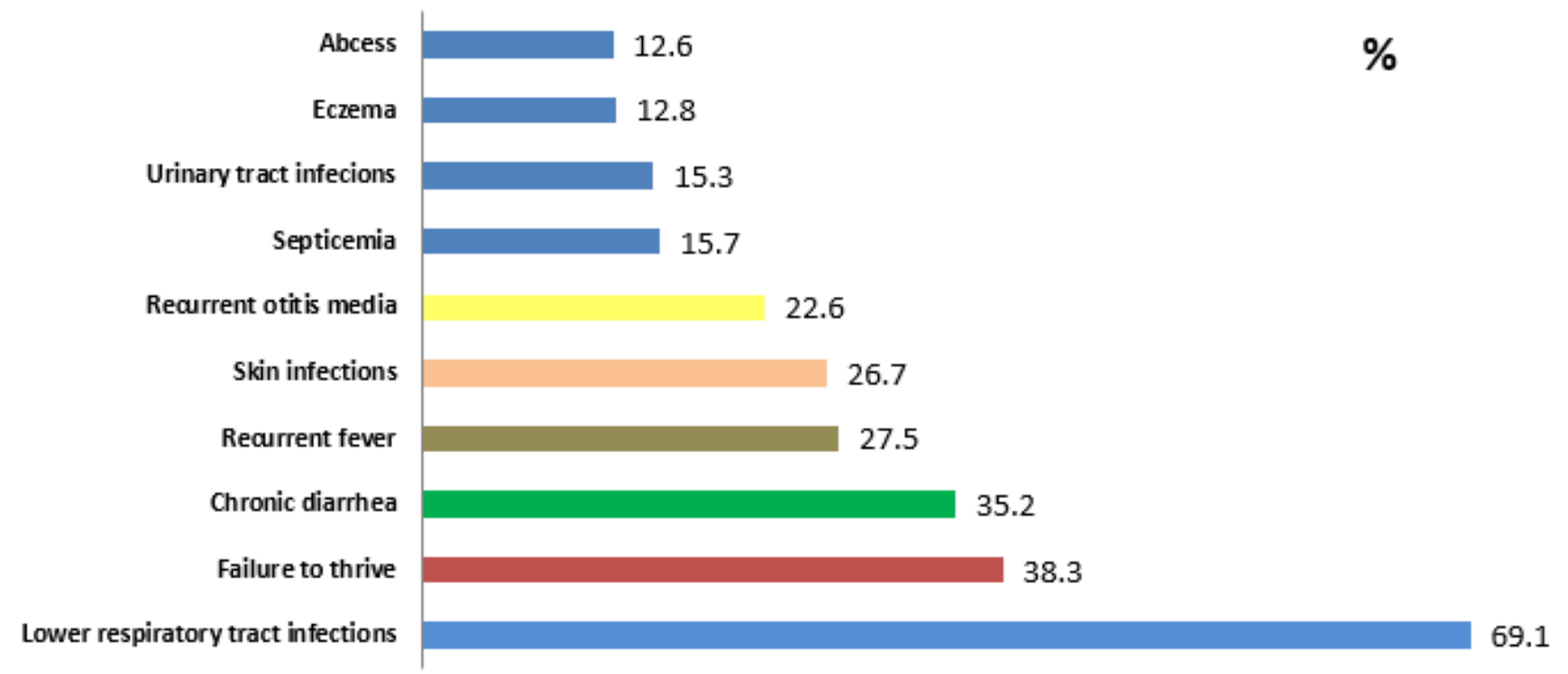


Figure 3

Main clinical signs observed at diagnosis

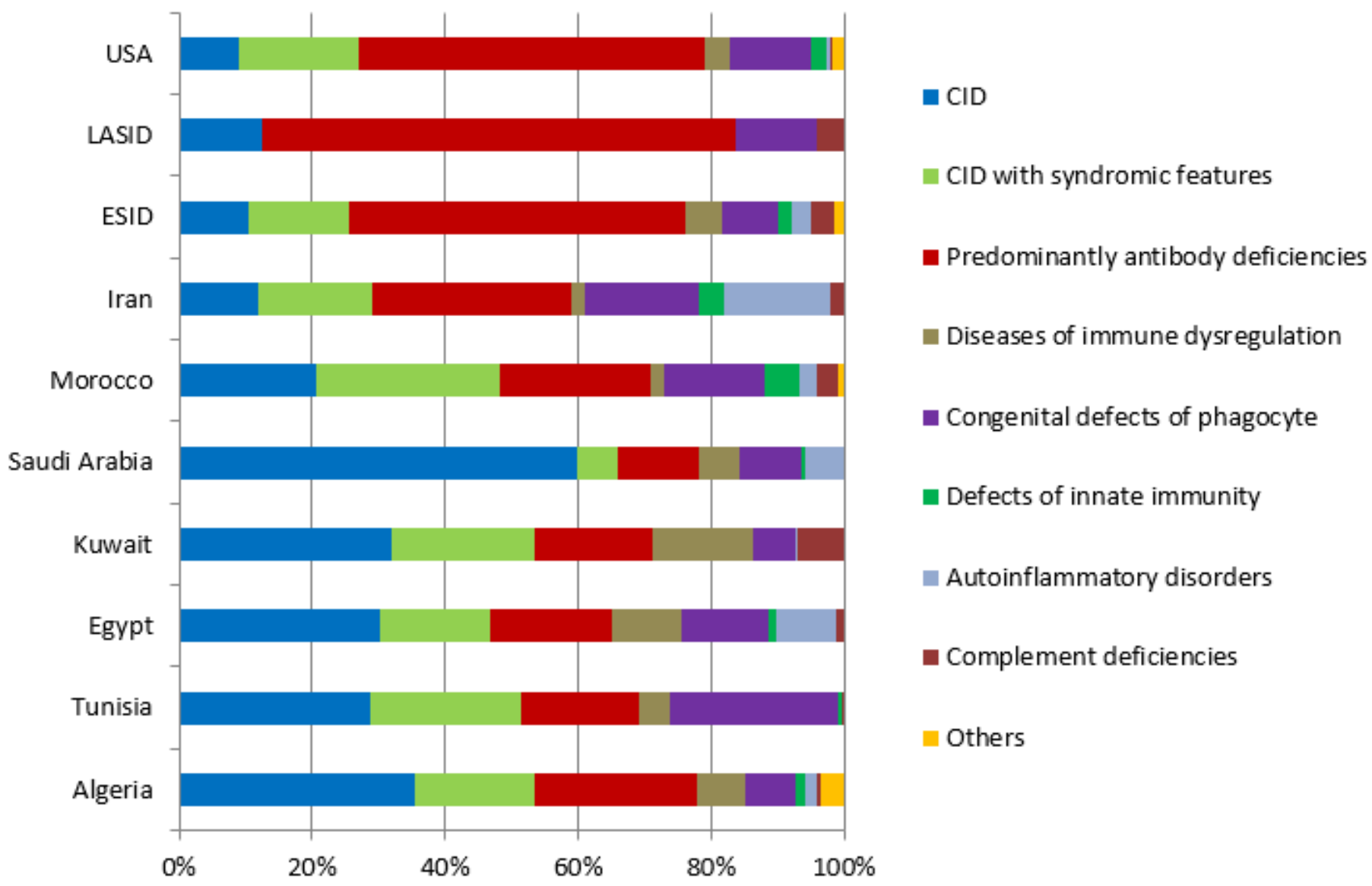

Figure 4

Comparison of the distribution of the predominant IEI categories between different registries. 